\title{
Occurrence of Waxes in Acinetobacter
}

\author{
By I. H. C. GALLAGHER* \\ Agricultural Research Council Meat Research Institute, Low Temperature \\ Research Station, Cambridge
}

(Accepted for publication 28 July I97I)

During a study of the effects of environmental temperatures on the composition of the fats in three strains of Acinetobacter (Gallagher, 1968) an unusual component was detected when lipid extracts were analysed by thin-layer chromatography. This component was shown to consist of a mixture of waxes. As waxes occur rarely in bacteria it was of interest to characterize them and to study the effect of incubation temperature on their composition.

\section{METHODS}

The three strains of Acinetobacter, G 37 (a mesophile), G 39 and G 249 (psychrotrophs with generation times of 43 and I $\mathrm{h}$. respectively at $\mathrm{I}^{\circ}$ ) belonged to phenon 4 of Thornley's ( 1967$)$ classification. The bacteria were grown aerobically at different temperatures in nutrient broth (Oxoid) containing $0.5 \%$ (v/v) Tween 80 (Dr M. J. Thornley, personal communication) at $\mathrm{pH} 7 \cdot 5$. Cells were centrifuged during the late exponential phase of growth, washed and freeze-dried.

Lipids in the lyophilized cells were extracted and washed by the methods of Folch, Lees \& Sloane Stanley (1957). The solution of fats was chromatographed on a silicic acid column by means of the procedure and simplified elution scheme of Hirsch \& Ahrens (1958). Waxes were recovered in the first solvent fraction.

Thin-layer chromatography (TLC) on silica gel $\mathrm{H}$ was carried out with one of the following solvent systems: solvent A, petroleum ether + diethyl ether +formic acid, 80:20: I (by vol.) (modified from Mangold, I96I); solvent B, petroleum ether + diethyl ether, 9: I (by vol.). Either chromic acid (Rouser, Galli, Lieber, Blank \& Privett, 1964) or fluorescent reagent (Neudoerffer \& Lea, I966) was used to detect lipids.

Samples to be analysed by gas-liquid chromatography (GLC) were inter-esterified with sodium methylate (de Man, 1964) and resolved on columns containing polyethylene glycol adipate (PEGA) or methyl silicone gum E30 (E30) according to the procedures of Neudoerffer \& Lea (1966).

The waxes, purified by column chromatography, were cleaved by sodium methoxide inter-esterification. Alcohols and methyl esters of fatty acids were recovered by extraction with petroleum ether and separated for subsequent analysis by TLC using solvent B.

For other analyses $4 \mathrm{mg}$. samples of waxes were saponified with $10 \mathrm{ml}$. of $3 \%(\mathrm{w} / \mathrm{v}) \mathrm{KOH}$ in $95 \%(\mathrm{v} / \mathrm{v})$ ethanol under reflux for $2.5 \mathrm{~h}$. After treatment, the non-saponifiable matter and the soaps were separated and the free fatty acids were recovered from the latter (Burchfield \& Storrs, 1962). Free fatty acids and non-saponifiable matter were refluxed in dry $5 \%(\mathrm{v} / \mathrm{v}) \mathrm{H}_{2} \mathrm{SO}_{4}$ in methanol (Neudoerffer, 1967$)$. The products were recovered and examined by GLC.

\footnotetext{
* Present address: Meat Industry Research Institute of New Zealand (Inc.), P.O. Box 6I7, Hamilton, New Zealand.
} 
As one confirmatory test for the presence of the hydroxyl group, the alcohols were treated with a mixture of hexamethyldisilazane + trimethylchlorosilane according to the manufacturer's instructions (Sil-Prep, Applied Science Laboratories, State College, Pennsylvania, U.S.A.). The resulting solution was analysed by GLC on PEGA and E 30 columns to detect a peak shift resulting from the formation of trimethylsilyl ethers.

Alcohols were purified by TLC, checked for purity by GLC and analysed as a liquid film $(0.05 \%, \mathrm{w} / \mathrm{v}$, in carbon tetrachloride) by means of an infrared recording spectrophotometer. Stearyl alcohol served as a standard.

\section{RESULTS}

Analysis by TLC, using solvent system A, showed that the single bacterial lipid in the first column fraction had a rate of movement of $I \cdot 30$ relative to the triglyceride standard. After cleavage of the fraction with sodium methoxide, the presence of two groups of components, alcohols and methyl esters of fatty acids, was established. The alcohols reacted with silylating reagent and the presence of the hydroxyl group was confirmed by its sharp peak at $3640 \mathrm{~cm} .^{-1}$, characteristic of the free-OH stretching frequency (Bellamy, I954).

Both alcohols and fatty-acid methyl esters were detected when the non-saponifiable residue from the waxes was methylated and analysed by GLC. This was good evidence that the alcohols were esterified with the fatty acids in the original material, the ester bond being resistant to saponification in a manner characteristic of that for waxes. Thus the first solvent fraction from the silicic acid column contained waxes. They occurred to the extent of 0.8 to $7.9 \%$ of the dry weight of the cell, the amount varying both with the strain and temperature of growth (Gallagher, 1968).

During GLC it was noted that a wide variety of saturated and mono-unsaturated alcohols, $\mathrm{C}_{3}$ to $\mathrm{C}_{5}$ and $\mathrm{C}_{8}$ to $\mathrm{C}_{20}$, occurred in the waxes of all three acinetobacters. Unsaturation ratios (moles mono-unsaturated alcohols: moles saturated alcohols) were calculated for the $\mathrm{C}_{8}$ to $\mathrm{C}_{20}$ alcohols from each organism: strain $\mathrm{G} 37,7.8\left(27^{\circ}\right)$ and $\mathrm{I} 3.7\left(\mathrm{I} 3^{\circ}\right)$; strain $\mathrm{G} 39,6.5\left(27^{\circ}\right)$ and $6.7\left(13^{\circ}\right)$; strain $\mathrm{G} 249,5.0\left(13^{\circ}\right)$ and $2.9\left(1^{\circ}\right)$. The effects of growth temperature differ in the acinetobacters. At low temperature there were appreciable increases in unsaturation in the mesophile (G 37) and small changes in $\mathrm{G} 39$, while the proportion of unsaturated long-chain alcohols decreased in G 249. However, in this latter organism (which grows relatively fast at $\left.I^{\circ}\right)$ the short-chain alcohols, $C_{3}$ to $C_{5}$, were very prominent. Peaks for the short-chain alcohols, $\mathrm{C}_{3}$ to $\mathrm{C}_{5}$ saturated and mono-unsaturated, occurred on the descending solvent peak on the GLC chart. Measurements of the peak areas for the individual compounds were approximate only. As a consequence, values for the $\mathrm{C}_{3}$ to $\mathrm{C}_{5}$ alcohols are presented collectively and are calculated as a percentage by weight of the total alcohols: strain $\mathrm{G} 37$, $2 \%\left(27^{\circ}\right)$ and $\mathrm{I} 2 \%\left(13^{\circ}\right)$; strain $\mathrm{G} 39,6 \%\left(27^{\circ}\right)$ and $23 \%\left(\mathrm{I} 3^{\circ}\right)$; strain $\mathrm{G} 249, \mathrm{I0} \%\left(\mathrm{I} 3^{\circ}\right)$ and $33 \%\left(1^{\circ}\right)$.

\section{DISCUSSION}

Waxes occur rarely in bacteria, traditionally being regarded as components of Corynebacterium diphtheriae and the mycobacteria (Asselineau, 1966). However, similar substances have been found recently in Nocardia (Lanéelle, Asselineau \& Castelnuovo, 1965) and their presence has been inferred in Bacillus cereus (Kates, Kushner \& James, 1962) and Serratia marcescens (Kates, Adams \& Martin, 1964). Unlike those of Acinetobacter, the alcohols in the other bacteria are mainly saturated (Asselineau, I966), although corinnic $\left(\mathrm{C}_{35}\right.$ monounsaturated) alcohol in $C$. diphtheriae is an exception (Gubarev \& Vakulenko, I945). Because of their apparently limited but perhaps increasingly recognized distribution, the 
waxes might profitably be examined for use in taxonomy. Perhaps the most interesting feature of the waxes is their high concentration of unsaturated medium- to long-chain alcohols, and, in the case of strain $\mathrm{G} 249$ at $\mathrm{I}^{\circ}$, large amounts of $\mathrm{C}_{3}$ to $\mathrm{C}_{5}$ alcohols. The variation of the alcohol composition of waxes with temperature does not appear to have been reported before, and one may speculate on possible reasons for the changes. Assuming that the alcohols are formed by reduction of the corresponding acids (Kolattukudy, I968), it may be that the enhanced solubility of oxygen at low temperature promotes greater synthesis of unsaturated alcohols in the mesophile, possibly acting as a self-regulatory system (Harris \& James, 1969). The increases in the proportions of the short-chain alcohols in all three organisms, not obviously related to oxygen solubility, suggest that the changes are a necessary adjustment to low temperature, perhaps affecting the functioning of a cellular organelle such as the membrane.

The author wishes to thank the Meat Industry Research Institute of New Zealand (Inc.) for a Research Fellowship, the Low Temperature Research Station, Cambridge for accommodation and facilities, and Drs A. G. Kitchell, M. J. Fishwick and P. A. T. Swaboda for their encouragement and guidance.

\section{REFERENCES}

Asselineau, J. (1966). The Bacterial Lipids. Paris: Hermann.

Bellamy, L. J. (1954). The Infra-red Spectra of Complex Molecules. London: Methuen.

BurChfield, H. P. \& STORRS, E. E. (1962). Biochemical Applications of Gas Chromatography. New York: Academic Press.

DE MAN, J. M. (1964). Determination of the fatty acid composition of milk fat by dual column temperature programmed gas-liquid chromatography. Journal of Dairy Science 47, 546-547.

Folch, J., Lees, M. \& SloAne Stanley, G. H. (I957). A simple method for the isolation and purification of total lipides from animal tissues. Journal of Biological Chemistry 226, 497-509.

GALlAGHER, I. H. C. (1968). A study of some psychrotrophic and related mesophilic bacteria of lamb carcass meat. Ph.D. Thesis, University of Cambridge.

Gubarev, E. M. \& Vakulenko, I. L. (1945). Nature and properties of lipids from Corynebacterium diphtheriae. Biochimia 10, 285-295.

Harris, P. \& JAMES, A. T. (I969). The effect of low temperatures on fatty acid biosynthesis in plants. Biochemical Journal 112, 325-330.

HiRSCH, J. \& Ahrens, E. H. (1958). The separation of complex lipid mixtures by the use of silicic acid chromatography. Journal of Biological Chemistry 233, 3 I I-320.

Kates, M., Adams, G. A. \& Martin, S. M. (1964). Lipids of Serratia marcescens. Canadian Journal of Biochemistry 42, 46I-479.

Kates, M., Kushner, D. J. \& JAmes, A. T. (1962). The lipid composition of Bacillus cereus as influenced by the presence of alcohols in the culture medium. Canadian Journal of Biochemistry and Physiology 40, 83-94.

Kolatrukudy, P. E. (1968). Biosynthesis of surface lipids. Science, New York 159, 498-505.

Lanḱelle, M.-A., Asselineau, J. \& Castelnuovo, G. (1965). Études sur les Mycobactéries et les Nocardiae. Annales de l'Institut Pasteur, Paris 108, 69-82.

MANGOLD, H. K. (1961). Thin-layer chromatography of lipids. Journal of the American Oil Chemists' Society 38, 708-727.

NeUDOERFFER, T. S. (1967). The influence of dietary fish oil on the composition of the lipids and volatile flavour compounds of turkey meat. Ph.D. Thesis, University of Cambridge.

NeUdoerfFer, T. S. \& LEA, C. H. (1966). Effects of dietary fish oil on the composition and stability of turkey depot fat. British Journal of Nutrition 20, $58 \mathrm{I}-594$.

Rouser, G., Galli, C., Lieber, E., Blank, M. L. \& Privett, O. S. (I964). Analytical fractionation of complex lipid mixtures: DEAE cellulose column chromatography combined with quantitative thin layer chromatography. Journal of the American Oil Chemists' Society 4r, 836-840.

ThornLey, M. J. (1967). A taxonomic study of Acinetobacter and related genera. Journal of General Microbiology 49, $211-257$. 